\title{
Cachaza y carbonilla: residuos agroindustriales con potencial de fertilización biológica nitrogenada
}

\section{Filter cake and ash carbon: agro-industrial wastes with potential for biological nitrogen fertilization}

\author{
Torta de filtro e cinza de carvão: resíduos agro-industriais \\ com potencial de fertilização biológica nitrogenada
}

\section{Sandra Patricia Montenegro Gómez ${ }^{1}$, Milton Cesar Ararat² \& Jhon Fredy Betancur ${ }^{3}$ \\ 'Licenciada en Biología y Química. Especialista en manejo y conservación de suelos y aguas. Ma- gister en ciencias agrarias, énfasis suelos. Ph. D. en Ciencias, área de concentración Microbiología \\ Agrícola. ${ }^{2}$ Ingeniero Agrónomo. Magister en ciencias agrarias, énfasis suelosPh. D. en Ciencias Agrarias, énfasis suelos. ${ }^{3}$ Ingeniero Agrónomo. Especialista en Biología Molecular y Biotecnología.}

Ph. D. en Ciencias Agrarias, énfasis fitomejoramiento.

${ }^{1}$ Centro de Investigación de Agricultura y Biotecnología-CIAB. Dosquebradas. Risaralda. Colombia. ${ }^{2}$ Facultad de Ciencias Agropecuarias. Universidad Nacional de Colombia-Sede Palmira ${ }^{3}$ Facultad de

Ciencias de la Salud. Universidad de Manizales.

1sandrapmontenegro@gmail.com, ${ }^{2 m}$ cararato@unal.edu.co, 3jbetancur@unimanizales.edu.co

\section{Resumen}

Fue evaluada la presencia de bacterias fijadoras de nitrógeno (diazotróficas) en tres mezclas de residuos con proporciones diferentes de compost de cachaza, arena y carbonilla; proporciones iguales de cascarilla de arroz y bagazo de caña: M1 (40, 10, 10, 20, 20 respectivamente), M2 (20, $0,40,20,20$ respectivamente), M3 (10, 40, 10, 20, 20 respectivamente). La evaluación se basó en la presencia del gen nifH, característico exclusivamente en bacterias diazotróficas. Se utilizó como control positivo muestras de ADN de bacterias del genero Azotobacter spp. Las mezclas con mayor contenido de cachaza y carbonilla M1 y M2, amplificaron para el gen nifH. Las bandas más fuertes se observan en M1 con mayor contenido de compost de cachaza. En contraste la mezcla M3, conformada principalmente por arena y cantidad muy inferior de residuos orgánicos no amplificó; sugiriendo que los contenidos de materia orgáni- ca, son relevantes para la presencia de bacterias diazotróficas y potencial estimulante de fijación biológica de nitrógeno.

Palabras clave: residuos orgánicos, biofertilización, fijación biológica de nitrógeno, bacterias diazotróficas, gen nifH

\section{Abstract}

It was evaluated the presence of nitrogen fixing bacteria (diazotrophic) in three mixtures with different proportions of waste filter cake, sand and coal ash; equal proportions of rice husks and sugar cane bagasse M1 (40, 10, 10, 20, 20 respectively), M2 (20, 0, 40, 20, 20 respectively) M3 (10, 40, 10, 20, 20 respectively). The evaluation was based on the presence of the gene nifH characteristic exclusively diazotrophic bacteria. Positive DNA samples of bacteria of the genus 
Azotobacter spp. was used as control. The mixtures more content filter cake and coal ash- M1 and $\mathrm{M} 2$, amplified or nifH gene. The strongest bands are observed in M1 with a higher content of filter cake. In contrast, the M3 mixture, consisting mainly of sand and much lower amount of organic waste not amplified; suggesting how the contents of organic matter are relevant to the presence of bacteria diazotrophic, and exciting potential of biological nitrogen fixation.

Key-words: organic wastes, biofertilization, biological nitrogen fixation, diazotrophic bacteria, nifH gene.

\section{Resumo}

Foi avaliada a presença de bactérias fixadoras de nitrogênio (diazotróficas) em três misturas de resíduos com diferentes proporções de torta de filtro, areia e cinza de carvão; proporções iguais de casca de arroz e bagaço de cana: M1 (40, 10,
$10,20,20$, respectivamente), $\mathrm{M} 2(20,0,40,20,20$, respectivamente) M3 $(10,40,10,20,20$, respectivamente). A avaliação baseou-se na presença do gene nifH característico exclusivamente em bactérias diazotróficas. Foi utilizado um controle positivo de ADN de bactérias do gênero Azotobacter spp. As misturas com maior conteúdo de torta de filtro e cinza de carvão- M1 e M2, amplificou para o gene nifH. As bandas mais fortes são observadas em M1 com maior teor de torta de filtro. Em contraste, a mistura M3, constituída principalmente de areia e em muito menor quantidade de resíduos orgânicos não amplificou; sugerindo que os conteúdos de matéria orgânica, são relevantes para a presença de bactérias diazotróficas e potencializam a fixação biológica de nitrogênio.

Palavras-chave: resíduos orgânicos, biofertilizantes, fixação biológica de nitrogênio, bactérias diazotróficas, gene nifH

\section{Introducción}

Por su contenido de humus, los biofertilizantes a partir de compostaje, son de gran utilidad en el acondicionamiento físico-químico del suelo, ligándose a sus partículas y contribuyendo principalmente en la retención de nutrientes y la aireación del mismo. No obstante, la dificultad de comercialización es un obstáculo, debido a que las concentraciones de nutrientes esenciales para las plantas, especialmente fósforo y nitrógeno son bajas (Ranco \& Urgel, 2001). Por su parte, la comunidad agricultora aún no se concientiza de que el nitrógeno $(\mathrm{N})$ adicionado a través de compost $\mathrm{o}$ cualquier fuente de materia orgánica, tiene poca influencia sobre la cantidad de nitrógeno en el suelo. Esta depende de la vida del suelo y su fijación por bacterias diazotróficas (Primavesi, 2009). Es así como el aporte nutricional no debe ser la característica fundamental del compost; sin embargo los microorganismos habitantes del mismo necesitan contenidos mínimos nutricionales para su desarrollo funcional (Primavesi, 2003). Bacterias heterótrofas se alimentan del Carbono de la materia orgánica para producción energética y usan rápidamente el $\mathrm{N}$ disponible para suplir sus necesidades de crecimiento, convirtiéndolo en un nutriente de difícil disponibilidad para las plantas (Sideman, 2007). Razón por la cual es de vital importancia estimular el crecimiento y actividad de bacterias diazotróficas y con ello promover la obtención de $\mathrm{N}$ necesario para el crecimiento de los cultivos. A este grupo microbiano pertenecen bacterias que fijan el $\mathrm{N}$ atmosférico y lo hacen asimilable a través de su reducción a forma amoniacal; cualidad atribuida a la actividad enzimática de la nitrogenasa, esta enzima utiliza por lo menos 16 moléculas de MgATP, por cada molécula de $\mathrm{N}_{2}$ reducida ó dos MgATP por electrón, tal como es representado en la ecuación (1) (Burgman, 2000). 


\section{$\mathrm{N}_{2}+10 \mathrm{H}++8 \mathrm{e}^{-}+\mathrm{nMgATP} \quad \Longrightarrow 2 \mathrm{NH}_{4}+\mathrm{H}_{2}+\mathrm{nMgADP}+\mathrm{nP} \quad(\mathrm{n} \geq 16)$}

La estructura, biosíntesis y regulación de la nitrogenasa, son determinadas por los genes nif, que son encontrados en todos los diazotróficos (de vida libre, asociativos y simbióticos). Los genes nifHDK son los responsables por codificar las proteínas estructurales del complejo enzimático, ejemplificado en la figura 1, en la bacteria KlebsieIla Penuominiae, en cuyo genoma fueron identificados por primear vez genes asociados a la fijación biológica de nitrógeno (FBN).

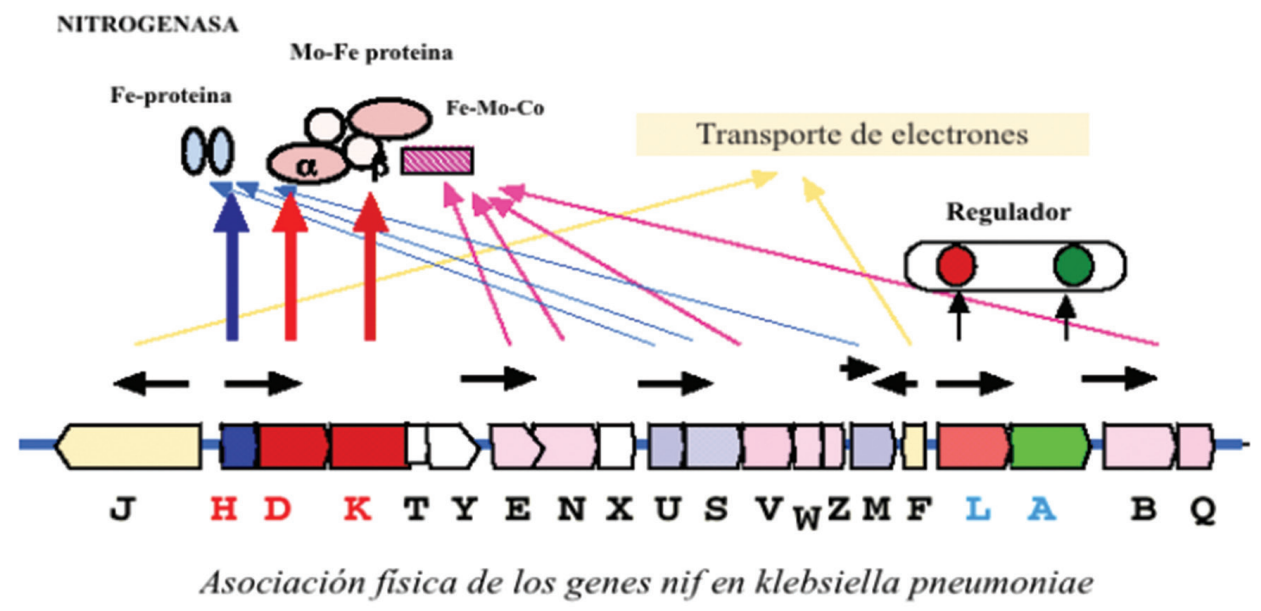

Figura 1. Organización de los genes nif en klebsiellapnuomoniae y sus funciones Fuente: Adaptado de http://www.asahi-net.or.jp/ it6i-wtnb/BNF.html

Diversos relatos de los beneficios de bacterias diazotróficas abren la posibilidad, para optimización de inóculos en diferentes cultivos. Por ejemplo se ha encontrado que diazotróficas no simbióticas sustituyen $60 \%$ de las necesidades de $\mathrm{N}$ en caña de azúcar, aproximadamente 200 $\mathrm{kg}$ de N/ha (Urquiaga et al., 1992). Cassetari (2014), en casa de vegetación, encontró una aproximación a estos resultados, en plántulas de caña de azúcar, en esta investigación se realizó inmovilización de células bacterianas en microesferas de alginato y posterior inoculación en el suelo, los resultados mostraron incremento significativo de masa seca en la parte aérea, raíces y concentración de $\mathrm{N}$ en fases tardías de desarrollo de la planta, cuando fue aplicado hasta el $50 \%$ de la fertilización nitrogenada recomendada para este cultivo.
Residuos de cachaza y carbonilla, son usados como biofertilizante, con resultados exitosos en diferentes cultivos. El objetivo del presente estudio fue evaluar la presencia de bacterias diazotróficas detectadas por genes nifH en este tipo de residuos mezclados entre sí y con adición de arena, cascarilla de arroz y bagazo de caña.

\section{Materiales y métodos}

\section{Implementación del experimento}

En el Centro Experimental de la Universidad Nacional de Colombia sede Palmira (CEUNP), Valla del Cauca, Colombia. Se establecieron tres mezclas de residuos en diferentes proporciones tal como se describe en la Tabla 1. 
Tabla 1. Mezclas de sustratos para detección de la presencia del gen nifH.

\begin{tabular}{l|cccccc}
\hline \multirow{2}{*}{ Mezclas } & \multicolumn{7}{c}{ Proporción (g) } \\
\cline { 2 - 7 } & $\begin{array}{l}\text { Compost } \\
\text { cachaza }\end{array}$ & Arena & Carbonilla & $\begin{array}{c}\text { Cascarilla } \\
\text { de Arroz }\end{array}$ & $\begin{array}{c}\text { Bagazo } \\
\text { de Caña }\end{array}$ & $\begin{array}{c}\text { Suelo } \\
\text { (Inceptisol) }\end{array}$ \\
\hline M1 & 40 & 10 & 10 & 20 & 20 & 0 \\
M2 & 20 & 0 & 40 & 20 & 20 & 0 \\
M3 & 10 & 40 & 10 & 20 & 20 & 0 \\
\hline Testigo & 0 & 20 & 0 & 20 & 20 & 40 \\
\hline
\end{tabular}

Fuente: Ararat (2013)

Los sustratos a evaluar y las mezclas establecidas se seleccionaron con el criterio de aporte de nutrientes y condiciones de mejoramiento en las propiedades físicas del suelo; por su parte el compost de cachaza es un residuo de la industria de caña de azúcar, empleado como enmienda húmica y la carbonilla es un residuo de caldera de las fábricas de ingenios azucareros, empleado como mejorador de la porosidad y el drenaje. Estos residuos se mezclaron en proporciones diferentes con arena y se les adicionó cascarilla de arroz y bagazo de caña en igual cantidad a todas las mezclas, con la finalidad de favorecer la aireación (Ararat, 2013).

\section{Extracción de ADN}

El DNA total fue extraído de $0.25 \mathrm{~g}$ de cada muestra, utilizándose el kit Power Soil DNA MoBio (MoBioLaboratories, Carlsbad, CA), de acuerdo con las instrucciones del fabricante. La integridad del DNA fue determinada por electroforesis en gel de agarosa 1\% en Tampón TAE 1x (Tris, Ácido Acético e EDTA), después coloreado con bromuro de etidio y posterior visualización en luz ultravioleta.

\section{PCR para amplificación del gen nifH}

La amplificación del gen dinitrogenasareductasa $($ nifH), se hizo de acuerdo a lo reportado por Rösch et al. (2002), donde se emplearon los iniciadores nifH-F AAA GGY GGW ATC GGY AAR TCC ACC AC y nifH-R TTG TTS GCS GCR TAC
ATS GCC ATC AT. La reacción de PCR se realizó con el kit GoTaq® Green Master Mix(Promega), adicionando $1.0 \mu \mathrm{M}$ cada iniciador, 50ng de ADN. Las condiciones de termociclaje que se llevaron a cabo fueron tomadas de acuerdo a lo reportado por Rösch et al. (2002) con algunas modificaciones. $94{ }^{\circ} \mathrm{C}$ por $3 \mathrm{~min}, 34$ ciclos de $94{ }^{\circ} \mathrm{C}$ por 45 segundos, $55{ }^{\circ} \mathrm{C}$ por 45 segundos y $72{ }^{\circ} \mathrm{C}$ por $1 \mathrm{~min}$; con una extensión final de $5 \mathrm{~min}$ a $72{ }^{\circ} \mathrm{C}$, el equipo usado para la amplificación fue un termociclador PTC100 (BioRad). Se utilizaron como control positivo muestras de ADN de la bacteria diazotrófica del genero Azotobacter spp. y como control negativo se utilizó la mezcla de reacción sin ADN. Los productos de PCR fueron analizados por electroforesis en gel de agarosa $1.0 \%$, donde se verificó la amplificación del fragmento de ADN de $0.3 \mathrm{~kb}$, concordante con el control positivo.

\section{Resultados y discusión}

Las mezclas M1 y M2, amplificaron para el gen nifH, (Figura 2), indicando la presencia de bacterias diazotróficas Las bandas más fuertes se observan en M1 con mayor contenido de compost de cachaza. Este residuo se caracteriza por altos contenidos de Carbono (C) y contenido de humedad superior al $60 \%$. En la presente investigación el contenido de $\mathrm{C}$ de cachaza y carbonilla de las mezclas podría considerarse el factor de mayor influencia para amplificación de nifH, esto lo refleja el contraste con M3, donde la proporción de estos 
residuos fue muy inferior (Tabla 1) y no se percibió la presencia de diazotróficos. Algunos estudios han demostrado que la variación en disponibilidad de $\mathrm{C}$, está relacionada con la colonización de comunidades diazotróficas (Nelson \& Mele, 2006;
Hsu \& Buckley, 2009; Tenget et al., 2009; Lindsay et al., 2010). En este caso es importante llevar a consideración el dominio de diazotróficos heterótrofos y su dependencia de la materia orgánica (Vitousek et al., 2000).

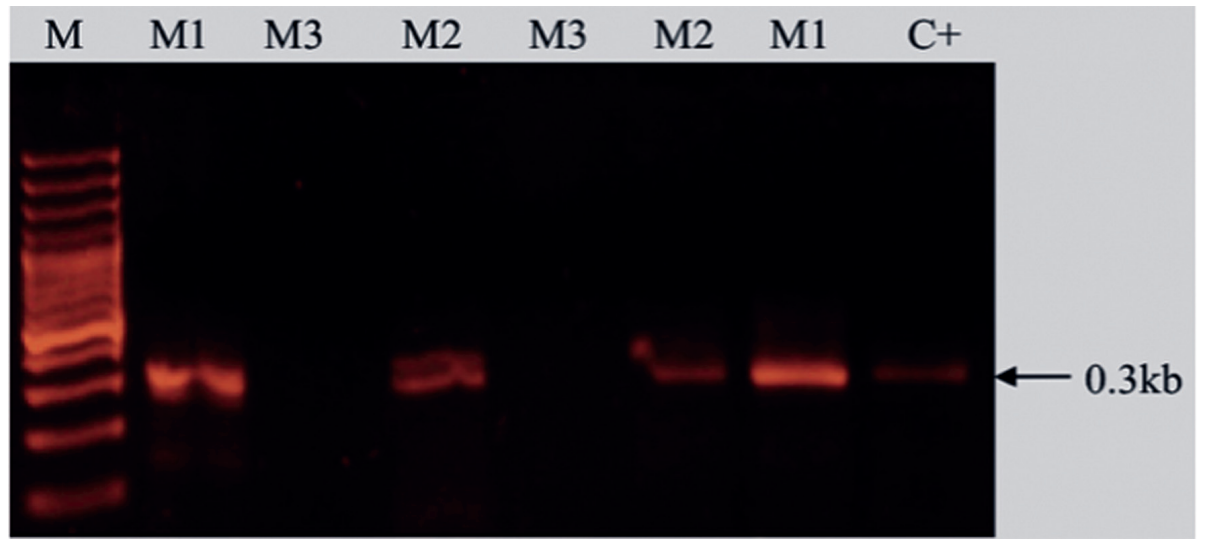

Figura 2. Amplificación del gen nifH en tres mezclas conformadas por compost de cachaza, arena, carbonilla, cascarilla de arroz y bagazo de caña. M1: 40-10-10-20-20. M2:20-0-40-20-20. M3:10-40-10-20-20, respetivamente. M: Marcador de Peso molecular. C+: Control positivo, Azotobacter spp.

Residuos compostados con altos contenidos de $\mathrm{N}$ inhiben la FBN. Por su parte sustancias orgánicas con amplia relación $\mathrm{C} / \mathrm{N}$, por ejemplo la paja de gramíneas, promueven esta dinámica, lo cual indica que en un compost, más que la riqueza de sus nutrientes, debe garantizarse la manutención en la nutrición microbiana (Primavesi, 1965; Glathe 1966). Un ejemplo según lo descrito por Hedin et al. (2009) se presentó en hojarasca en avanzado estado de descomposición donde altas relaciones $\mathrm{C} / \mathrm{N}$ aumentaron la demanda de $\mathrm{N}$ y aumento de la FBN (Reed et al., 2007). La relación $\mathrm{C} / \mathrm{N}$ de los residuos aquí estudiados, presentó 18.48 y 12.4 para compost de cachaza y carbonilla respectivamente (Tabla 2), sugiriendo almacenamiento de $\mathrm{C}$ y potencialidad promotora de FBN, principalmente el compost de cachaza.

Tabla 2. Composición carbonada y nitrogenada en compost de cachaza y carbonilla.

\begin{tabular}{lcccc}
\hline Determinación\%Sustrato & M. O & C & N-Total & C/N \\
\hline Compost de cachaza & 30.61 & 17.75 & 0.96 & 18.48 \\
Carbonilla & 4.28 & 2.48 & 0.20 & 12.4 \\
\hline
\end{tabular}

Fuente: Ararat (2013)

Estudios indican que además del $\mathrm{C}$ y $\mathrm{N}$, existe un conjunto de posibles controles sobre la FBN (por ejemplo, $\mathrm{P}, \mathrm{Mo}, \mathrm{O}_{2}$, Humedad, Temperatura). En este estudio los residuos presentaron 9.61 y 1.66 $\mathrm{mg} / \mathrm{kg}$ de $\mathrm{P}$ en Carbonilla y compost de cachaza respectivamente, estos resultados sugieren que la presencia de bacterias diazotróficas no estuvo asociada a mayores contenidos de $\mathrm{P}$ en el sustrato. 
Por su parte, la humedad también puede regular y aumentar la FBN (Roskoski, 1980; Chapin et al., 1991; Hofmockel \& Schlesinger 2007; Reed et al., 2007a), esta condición puede haber influenciado la presencia de diazotróficos en el compost de cachaza, caracterizado por presentar contenidos de humedad entre $60 \%$ y $70 \%$. En lo que respecta al Oxigeno es de suma importancia y se recomienda que cualquier material orgánico debe ser aplicado en forma superficial para mantener el sistema aerobio y promover la FBN durante el proceso de descomposición aerobia (Primavesi, 2009). Trabajos recientes sugieren que modelos conceptuales que integran múltiples controles en una estequiométrica perspectiva, pueden ofrecer una mejor visión de la FBN (Reed et al.; 2011).

Avanzar hacia el conocimiento sobre potencialización de bacterias diazotróficas e interacción con diversos cultivos, es tema de investigación a nivel mundial; debido al potencial biotecnológico evidenciado en el aumento de la productividad agrícola, posibilidad de reducción de costos de producción por disminución en el uso de abonos nitrogenados y consecuentemente conservación de los recursos ambientales (Moreira et al., 2010).

\section{Conclusiones}

Residuos constituidos por compost de cachaza y Carbonilla (M1, M2) amplificaron para el gen nifH, indicando la presencia de bacterias diazotróficas, El compost de cachaza mostró amplificación más fuerte. En contraste la mezcla M3, con cantidad muy inferior de estos residuos no amplificó. Los resultados obtenidos sugieren, que contenidos de materia orgánica deben ser considerados para promover la presencia de bacterias diazotróficas.

A pesar de la relevancia de los resultados, este tipo de estudios debe ser complementado con análisis funcionales de los genes nif, ya que la FBN responde a la actividad de la nitrogenasa, la cual por su condición enzimática es sensible a diversos factores bióticos o abióticos de inhibición o activación.

\section{Agradecimientos}

Los autores agradecen a: Corporación BIOTEC, vivero PROFRUTALES LTDA., Dr. Juan Carlos Menjivar Flores (Docente Universidad Nacional de Colombia).

\section{Referencias}

1. Ararat, M. C. (2013) Influencia de la nutrición mineral y la actividad biológica rizosférica en la disminución del daño ocasionado por Phytophthoracinnamomi Rands en plántulas de Aguacate (Persea americana Mill). (Tesis de Doctorado) Universidad Nacional de Colombia.

2. Bürgmann, H. (2003). Activity and diversity of nitrogenfixingmicroorganisms: novel toolstocharacterizepopulations in soil..Dissertation (Doctor in Science) - Swiss Federal Institut of TechnologyZurich, Zurich.

3. Cassetari, A. (2014). Fixação biológica de nitrogênioem cana-de-açúcar inoculada combactériasdiazotróficas. (Tesis de Doctorado en Suelos y nutrición de plantas), Escola Superior de Agricultura "Luiz de Queiros", Piracicaba, SP, Brasil.

4. Chapin FS, Bliss LC. \& Bledsoe LJ. (1991). Environmentalregulation of nitrogenfixation in a higharcticlowlandecosystem. Can. J. Bot. 69:2744-55.

5. Glathe, H \& Glathe,G. (1996). Bedeutung der mikroorganismenfür die nährstoffumsetzungimboden In: Sharrer- linser, handbuch der pflanzenernährungunddüngnung. New York: SpringerWien. p.626-642.

6. Hedin, L.O; Brookshire, E.N.J.; Menge, D.N.L. \& Barron, A.R. (2009). Thenitrogenparadox in tropical forestecosystems. AnnualReview of Ecology, Evolution, and Systematics, New Yorkv. 40, p. 613-635.

7. Hofmockel KS, \& Schlesinger WH. (2007). Carbondioxideeffectsonheterotrophicdinitrogenfixation in a temperatepineforest. SoilSci. Soc. Am. J. 71:140-44.

8. Hsu, S.F. \& Buckley, D.H. (2009). Evidenceforthefunctionalsignificance of diazotrophcommunitystructure in soil. The ISME Journal, New York, v. 3, p. 124-136.

9. Lindsay, E.A.; Colloff, M.J.; Gibb, N.L. \& Wakelin, S.A. (2010). Theabundance of microbialfunctional genes in grassywoodlandsisinfluenced more bysoilnutrientenrichmentthanbyrecentweedinvasionorlivestockexclusion. Applied and Environmental Microbiology, Washington, v.76, p. 5547-5555.

10. Moreira, F.M.; Da Silva, K.; Nóbrega, R.S. \& Carvalho, F. (2010). Bactériasdiazotróficasassociativas: diversidade, ecologia e potencial de aplicações. ComunicataScientiae, Piuaí, v. 1, n. 2, p. 74-99.

11. Nelson, D.R. \& Mele P.M. (2006). Theimpact of cropresidueamendments and lime onmicrobialcommunitystructure and nitrogen-fixing bacteria in thewheatrhizosphere. SoilResearch, Crawley, v.44, p. 319-329.

12. Primavesi, A. (1965). Microbiologia do solo. Santa Maria: Palotti. 
13. Primavesi, A. (2003). Revisão Do Conceito De Agricultura Orgânica : Conservação Do Solo E Seu Efeito Sobre a Água. Biológico, São Paulo, v.65, n.1/2, p.69-73, Jan./dez., 2003, 65, p. 69-73.

14. Primavesi, A. (2009). Cartilha do solo Como reconhecer e sanar seus problemas, 71.

15. Ranco, S. A. M. U. B., \& Urgel, P. A. H. E. M. (2001). Artigo técnico compostagem : solubilização biológica de rocha fosfática na produção de fertilizante o rganomineral, 6, p. 115-122.

16. Reed, S.C.; Cleveland, C.C. \&Townsend, A.R. (2007a). Controlsoverleaflitter and soilnitrogenfixation in twolowland tropical rain forests. Biotropica, Malden, v. 39, p. 585-592.

17. Reed, S.C; Cleveland, C.C. \& Townsend, A.R. (2011). FunctionalEcology of Free-Living NitrogenFixation: A ContemporaryPerspective. Annual Review of Ecology, Evolution, and Systematics, New York, v. 42, p. 489-512.

18. Rösch, C., Mergel, A., and Bothe, H. (2002). Biodiversity of denitrifying and dinitrogen-fixing bacteria in an acid forest soil. Appl. Environ. Microbiol. 68, p. 3818-3829

19. Roskoski JP. 1980. Nitrogenfixation in hardwoodforests of thenortheasternUnitedStates. PlantSoil 54. p. 3-44
20. Sideman, E. (2007). Providing Nitrogen to Organic Crops. MOFGA Fact Sheet, 8, p. 8-10.

21. Teng Q.H; Sun B.; Fu XR; LI SP; Cui Z.L.; Cao H. (2009). Analysis of nifHgene diversity in red soilamendedwithmanure in Jiangxi, south China. J. Microbiol. Nanjing, v.47 p. 135-141.

22. Urquiaga, S.; Cruz, K. H. S.; Boddey, R. M. (1992). Contribution of nitrogenfixationtosugarcane nitrogen-15 and nitrogen balance estimates. Soil Science Society American Journal, v.56, n. 1, p. 105-114.

23. Vitousek, V.; Hobbie, S. (2000)Heterotrophicnitrogenfixation in decomposinglitter: patterns and regulation. Ecology, Davis, v. 81, p. 2366-2376.

\section{Conflicto de Intereses}

Los autores declaran no tener ningún conflicto de intereses 
